\title{
A SOUTHERN HEMISPHERE RECORD OF THE MATUYAMA-BRUNHES POLARITY REVERSAL
}

\author{
Bradford M. Clement \\ Department of Geology, Florida International University
}

Dennis V. Kent

Lamont-Doherty Geological Observatory and Department of Geological Sciences, Columbia University

\begin{abstract}
We present a record of the Matuyama-Brunhes $(0.73 \mathrm{Ma})$ polarity transition from a southern hemisphere deepsea sediment core $\left(\mathrm{V} 16-58 ; 46^{\circ} \mathrm{S}, 30^{\circ} \mathrm{E}\right)$. The transition is recorded across at least $30 \mathrm{~cm}$ of section and is defined by a nearly $180^{\circ}$ change in directions which occurs during a low in the relative intensities. An increase in the $10 \mathrm{Be} / 9 \mathrm{Be}$ ratios associated with the intensity low suggests that the relative intensities may document a decrease in the strength of the geomagnetic field. The virtual geomagnetic pole (VGP) path is neither clearly near- or far-sided, but tracks approximately $120^{\circ}$ west of the site longitude. Considered with other MatuyamaBrunhes transition records, this southern hemisphere record supports previous interpretations that the Matuyama-Brunhes transitional field was not dipolar. Instead, the V16-58 transition together with other records of this reversal recently obtained from this longitudinal sector suggests that nonzonal terms which are symmetric about the equator were important during this transitional field.
\end{abstract}

\section{Introduction}

Our present understanding of the morphology of the geomagnetic field during a polarity reversal is limited because it has proven difficult to obtain well documented transition records of the same reversal from widely distributed site locations. The Matuyama-Brunhes reversal is documented by a number of transition records from widely spaced sampling localities [Valet et al., 1988; Valet et al.,1989; Bogue and Hoffman, 1987; Clement and Kent, 1986, Clement et al., 1982, Niitsuma, 1981, and Fuller et al., 1979], however, a detailed record has not been obtained from a southem hemisphere site. Therefore it has not been possible to constrain even the most fundamental symmetries with respect to the Equator in this transitional field. Accordingly we conducted a detailed paleomagnetic study of the Matuyama-Brunhes reversal as recorded in deep-sea sediment piston core V16-58 $\left(46^{\circ} \mathrm{S}, 30^{\circ} \mathrm{E}\right)$, which was taken from the Southwestern Indian Ocean.

\section{Methods}

We sampled continuously across the $44 \mathrm{~cm}$ section of sediment spanning the Matuyama-Brunhes polarity reversal by slicing approximately $0.5 \mathrm{~cm}$ thick wafers from the dried split half of the core. Each wafer was subdivided where possible into two to three specimens per stratigraphic level to allow a measure of the internal consistency of the results. Unfortunately because of the condition of the core it was not possible to continue detailed sampling further up or down-core. These sediments are weakly magnetized with natural remanent magnetization (NRM) values ranging from $5.5 \times 10^{-6} \mathrm{Am}^{2} / \mathrm{kg}$ to $4.0 \times 10^{-7} \mathrm{Am}^{2} / \mathrm{kg}$. While these magnetizations may be readily measured using a cryogenic magnetometer, after treatment at peak alternating fields (AF) of $40 \mathrm{mT}$ or greater

Copyright 1991 by the American Geophysical Union.

Paper number 90GL02714

$0094-8534 / 90 / 90 \mathrm{GL}-02714 \$ 03.00$ the magnetizations of the more weakly magnetized samples drop to values approaching the instrumental noise level. For this reason we subjected 5 pilot samples to detailed progressive AF demagnetization at increments of $2.5 \mathrm{mT}$ up to $50 \mathrm{mT}$, and the remaining samples were demagnetized at increments of 5 to $20 \mathrm{mT}$ up to peak fields of $40 \mathrm{mT}$ to $50 \mathrm{mT}$. In order to determine if important changes in the rock magnetic carriers occur across this interval we induced laboratory anhysteretic remanent magnetizations (ARMs) to one specimen per level using a $200 \mathrm{mT}$ peak alternating field in the presence of a coaxial $0.05 \mathrm{mT}$ DC field. We then partially $\mathrm{AF}$ demagnetized the ARMs at $20 \mathrm{mT}$ to allow direct comparison with the NRM intensities observed after partial demagnetization at this same level.

\section{Record of Transitional Field Behavior}

Results of progressive AF demagnetization (Figure 1) demonstrate that in samples yielding both full polarity as well as intermediate directions, characteristic magnetizations are isolated by treatment at peak fields of $20 \mathrm{mT}$. We calculated unit vector means of the characteristic directions and arithmetic averages of intensities obtained from the specimens from each stratigraphic level. It was not possible to isolate a characteristic remanence from specimens taken from one side of the core, and therefore we did not include the results from these specimens in our analysis. We suspect that the sediment in this part of the core was remagnetized during the coring process or that part of the disturbed rind of the core may have been sampled inadvertently.

The characteristic directions define a transition from reverse polarity to normal polarity which occurs across approximately $30 \mathrm{~cm}$ of section (Figure 2). The directional change is characterized by a rapid inclination change which takes place as the declinations gradually progress through westerly values.

The inclinations remain relatively stable about the reverse polarity mean of $62^{\circ}$ from the base of the sampled section $(1143 \mathrm{~cm})$ up to a depth of $1131.3 \mathrm{~cm}$. Between 1131.3 and $1129.4 \mathrm{~cm}$ the inclinations pass through the horizontal and approach values of the full normal polarity mean $\left(-62^{\circ}\right)$. Above this depth the inclinations then appear to oscillate, the directions progressing to shallow values $\left(-17^{\circ}\right)$ and then back to full polarity values. These inclination swings occur three times before the inclinations stabilize about the normal polarity value. Each of these inclination swings spans approximately 4 to $5 \mathrm{~cm}$.

The declinations exhibit a westerly change of more than 162 degrees from 1137.6 to $1108 \mathrm{~cm}$, bringing the total directional change to within $10^{\circ}$ of fully antipodal directions. The change in declinations is gradual thereby making it difficult to assign a lower boundary to the transition zone. Therefore we uniformly rotated the declinations in this azimuthally unoriented core to bring the normal polarity declinations (between 1099 and $1106 \mathrm{~cm}$ ) into best agreement with $0^{\circ}$. Full reverse polarity directions may not have been recorded in the sampled interval although the mean of the directions $\left(\mathrm{dec}=198.4^{\circ}\right.$, inc $=62^{\circ}, \alpha_{95}=5.0^{\circ}$ ) obtained from the interval between 1143.4 and $1137.6 \mathrm{~cm}$ falls less than $10^{\circ}$ of arc from the expected full polarity direction for this site location $\left(\mathrm{dec}=180^{\circ}\right.$, inc $\left.=64^{\circ}\right)$. 

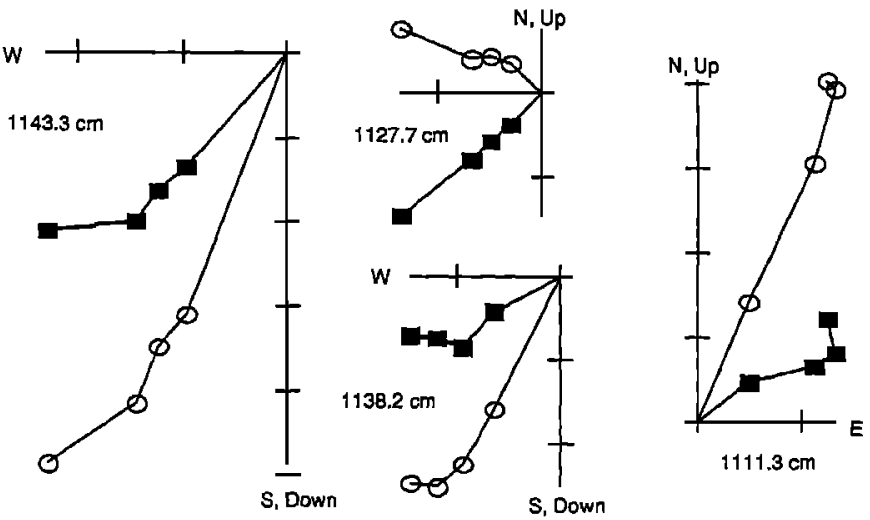

Fig. 1. Vector endpoint diagrams illustrating the response of specimens to progressive AF demagnetization. The results from specimens yielding reverse $(1143.3 \mathrm{~cm})$, intermediate $(1138.2 \mathrm{~cm}$ and $1127.7 \mathrm{~cm})$ and normal polarity $(1111.3 \mathrm{~cm})$ directions are shown plotted at the same scale. Each tick mark represents $1 \times 10^{-6} \mathrm{Am} 2 / \mathrm{kg}$. Solid squares (open circles) represent projection on the horizontal (vertical) plane.
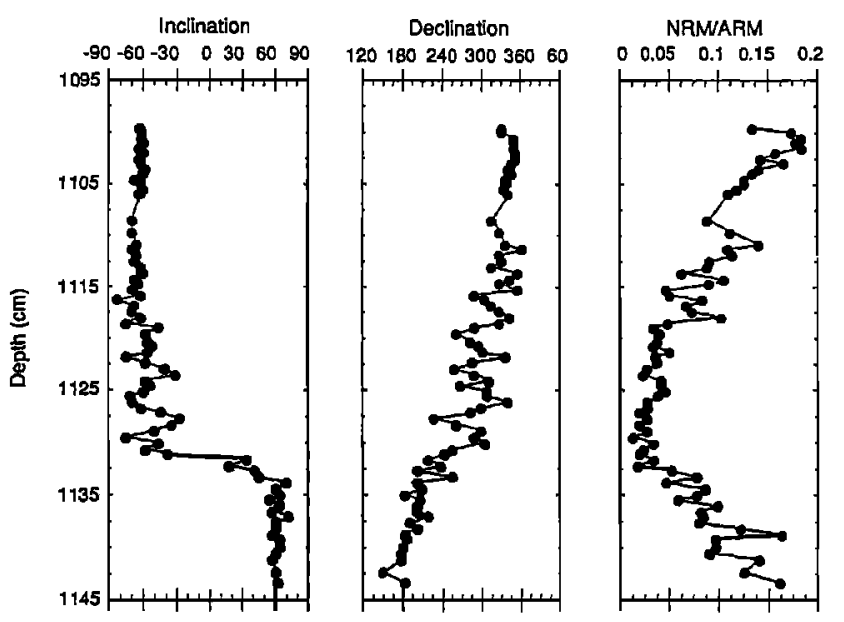

Fig. 2. Unit vector mean directions and normalized intensity from each stratigraphic level plotted versus subbottom depth. Inclinations and declinations are plotted in degrees. NRM intensity after partial AF demagnetization at $20 \mathrm{mT}$ normalized by ARM intensity after treatment at $20 \mathrm{mT}$ represents our best estimate of relative geomagnetic intensity variations across this interval.

In a manner similar to the inclinations, the declinations also exhibit oscillations as defined by swings of $40^{\circ}$ to $50^{\circ}$ which occur across approximately $4 \mathrm{~cm}$ of section. Five of these oscillations are well defined within the transition zone, but the amplitudes appear to diminish as full normal polarity values are approached.

The NRM intensities after partial AF demagnetization at 20 $\mathrm{mT}$, normalized by the ARM intensities after treatment at 20 $\mathrm{mT}$, represent our best estimate of the relative changes in geomagnetic field intensity across this interval (Figure 2). The ARMs of samples remain relatively constant across the sampled interval (mean $=2.577 \times 10^{-6} \mathrm{Am}^{2} / \mathrm{kg}$, standard deviation $=0.314 \times 10^{-6} \mathrm{Am}^{2} / \mathrm{kg}$ ), suggesting that variations in the NRM intensities are not likely to result from changes in the amount or nature of the magnetic carrier in these sediments. The normalized intensity record exhibits a pronounced low which is coincident with the directional change. Moving upcore the normalized intensities fall by more than $75 \%$ by $1132.2 \mathrm{~cm}$ and remain low until $1119.0 \mathrm{~cm}$ at which point the values begin to increase again. The intensity change may extend across a thicker interval than the directional change because the lower bound of the intensity change is not well constrained and may actually occur below the sampled interval.

Additional evidence supporting the interpretation of the relative intensity low as a decrease in geomagnetic intensity is provided by variations in the relative concentrations of $10 \mathrm{Be}$ across this interval. ${ }^{10} \mathrm{Be}$ is a cosmogenic isotope which should be produced in greater quantity during intervals of low geomagnetic intensity. Raisbeck et al. [1985] reported a relative increase in $10 \mathrm{Be}$ concentration associated with the Matuyama-Brunhes reversal in core V16-58. The $10 \mathrm{Be}$ concentrations normalized by $9 \mathrm{Be}$ concentrations are plotted in Figure 3 with the magnetization intensities. The $10 \mathrm{Be} / 9 \mathrm{Be}$ ratios increase from values of about $3 \times 10^{-8}$ to greater than 6 $x 10^{-8}$ from $1140 \mathrm{~cm}$ to $1135 \mathrm{~cm}$, and then decrease to about 3 x $10^{-8}$ by $1105 \mathrm{~cm}$. Raisbeck et al. [1985] noted that a threefold increase in $10 \mathrm{Be}$ production would be expected if the geomagnetic field intensity dropped to zero. The approximately factor of 2 increase in the ${ }^{10} \mathrm{Be} / \mathrm{Be}$ ratios is roughly coincident with the factor of 6 decrease in the relative intensities, however, the maximum $10 \mathrm{Be} / 9 \mathrm{Be}$ value occurs approximately $20 \mathrm{~cm}$ upcore from the intensity minimum. This offset is consistent with recent estimates of the lock-in depth of postdeposition remanent magnetization in deep-sea sediments [deMenocal et al., 1990].

Our best estimate of sedimentation rate across the section recording the Matuyama-Brunhes reversal in V16-58 comes from paleotemperature studies [Morley and Hays, 1976; J. Morley, personal communication, 1990]. These results place the top of oxygen isotope stage $17(627 \mathrm{kyx})$ at $865 \mathrm{~cm}$ and the top of stage $19(688 \mathrm{kyr})$ at $1110 \mathrm{~cm}$, yielding an estimate of the sedimentation rate of $4.0 \mathrm{~cm} / \mathrm{kyr}$. Given this sedimentation rate each $0.5 \mathrm{~cm}$ thick sample averages over approximately 125 years. As discussed above the total directional change associated with the polarity reversal is gradual and the exact placement of the boundaries of the transition zone is somewhat arbitrary. If the boundaries of the polarity transition zone as defined by the directional data are placed at 1138 and $1108 \mathrm{~cm}$ we obtain a duration of 7500 years; the duration of the intensity change, assuming that transitional field intensities span 1143.3 to $1108 \mathrm{~cm}$, is 8800 years.

\section{Virtual Geomagnetic Poles}

The record of the Matuyama - Brunhes transition presented here provides much needed constraint upon possible

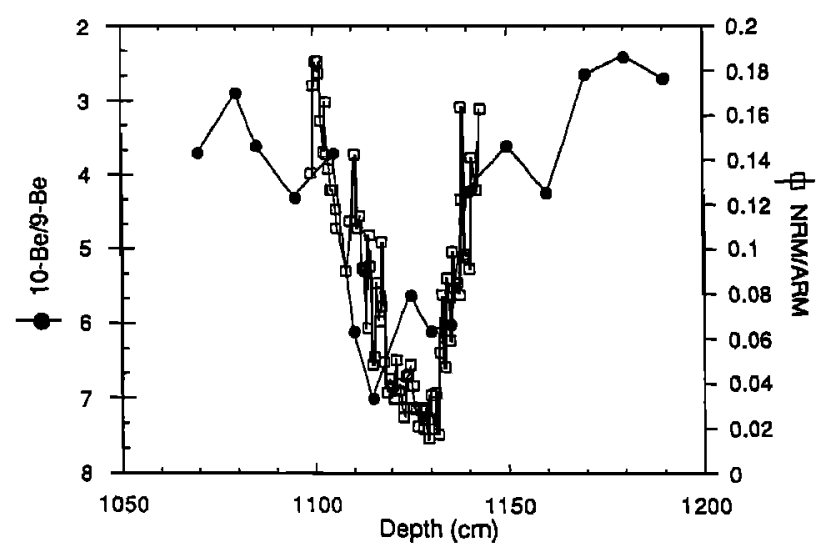

Fig. 3. Normalized intensity (NRM/ARM; open squares) plotted with ${ }^{10} \mathrm{Be} / 9 \mathrm{Be}$ ratios (solid circles) [Raisbeck et al., 1985]. Note the inversion of $10 \mathrm{Be} / 9 \mathrm{Be}$ scale. These data suggest an increased production of cosmogenic ${ }^{10} \mathrm{Be}$ during the geomagnetic intensity low associated with the reversal. 
symmetries with respect to the Equator. If the MatuyamaBrunhes transitional field was dominated throughout by dipolar fields, the VGP paths from different locations should coincide. If the transitional field was purely axisymmetric, then this record from the southern hemisphere together with the existing Matuyama-Brunhes records from the northern hemisphere would fully constrain low-degree, non-dipolar zonal field models [Hoffman, 1977; Hoffman and Fuller, 1978, Fuller et al, 1979; Williams and Fuller, 1981]. These models predict that sites from both hemispheres should exhibit the same transitional VGP path if the field were dominated by geometries which are symmetric with respect to the Equator (such as quadrupolar fields). If antisymmetric geometries (such as octupolar fields) dominated the transitional field then VGP paths from sites in opposite hemispheres would exhibit opposite sidedness.

We calculated VGP positions across the Matuyama-Brunhes transition in V16-58 using the declination adjusted mean directions from each stratigraphic level. The resulting VGP path is longitudinally constrained, with transitional VGP longitudes ranging from $280^{\circ} \mathrm{E}$ to $343^{\circ} \mathrm{E}$ (Figure 4). The path is centered over the $300^{\circ}$ meridian; the VGPs track northward through South and North America. The VGP path from V1658 is neither clearly near- or far-sided but falls, on average, $120^{\circ}$ west of the site location, suggesting that nonaxisymmetric geometries must have played an important role in this transitional field.

If we compare the transition from V16-58 with two other records of the Matuyama-Brunhes reversal obtained recently from the same longitudinal sector, an interesting symmetry with respect to the Equator emerges. The VGP path from V1658 falls very close to the VGP path obtained from deep-sea sediments cored at DSDP Site 609 in the North Atlantic $\left(49^{\circ} \mathrm{N}\right.$, $335^{\circ} \mathrm{E}$; [Clement and Kent 1986]) which also tracks northward through the Americas. These paths, however, differ from those obtained from ODP Site $664\left(0.06^{\circ} \mathrm{N}, 337^{\circ} \mathrm{E}\right.$; [Valet et al, 1989]) in the Equatorial Atlantic and a less detailed record from ODP Site $659^{\circ}\left(18^{\circ} \mathrm{N}, 339^{\circ} \mathrm{E}\right.$; [Valet et al., 1989]) which track northward through Asia. These records were obtained using similar methods, from sites which are separated by less than $60^{\circ}$ of longitude. Although each of these VGP paths displays portions which are constrained with respect to longitude, it is difficult to explain the longitudinal distribution of these paths as resulting from a smoothing process such as that suggested by Rochette [1990]. The differences between the VGP paths obtained from the mid-latitude and equatorial sites support previous interpretations that dipolar fields were not dominant during this reversal [Valet et al., 1988; Valet et al., 1989]. Instead, when the records from the Atlantic sector are considered together, a distinct symmetry about the Equator becomes apparent with the equatorial record exhibiting a VGP path which is nearly antipodal to the VGP paths from the midlatitudes of the northem and southern hemispheres.

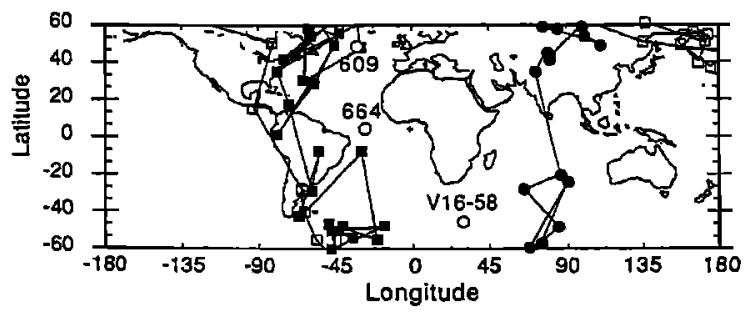

Fig. 4. Matuyama-Brunhes VGP paths from V16-58 indcated by solid squares, from DSDP site 609 indicated by open squares, and from ODP Site 664 indciated by solid circles. The site locations are indicated by open circles. The VGP paths from the mid-latitude sites pass through the Americas whereas the path from the Equatorial Atlantic falls close to the $90^{\circ}$ Meridian, nearly antipodal to the paths from the midlatitude sites.

\section{Discussion}

The symmetry with respect to the Equator observed along this longitudinal transect indicates that the Matuyama-Brunhes transitional field was not dominated by dipolar terms, but instead that higher degree, non-dipole fields must have been important during this reversal. This result appears to limit the use of VGP paths in interpreting transition records, however VGPs may still provide insights into the geometries of transitional fields in geographical coordinates. If the transitional field symmetries were sufficiently large scale, then VGPs provide a gross indication of the location of the nearest magnetic dip pole to the site location. This information can be used to infer the sense of symmetry of the non-dipole field. Because the relation between the magnetic dip poles and the directions observed at the site is nonlinear for dipolar (as well as more complex) geometries, it is necessary to then test the inferred sense of symmetry by calculating the VGP position which would be observed at a site, given a non-dipole geometry specified in terms of spherical harmonics. It is interesting to note that the lowest degree non-zonal, nondipolar term, $h_{2}^{l}$, evidence of which was suggested by two independent studies of the time averaged paleomagnetic field [Livermore $e t$ al.1983; Schneider and Kent 1990], may account for several features of this transitional field as defined by these three records. If an $h_{2}^{l}$ term is superimposed upon a reversing axial dipole using the method of Williams and Fuller [1981], the resulting synthetic VGP paths tend to cluster about the $90^{\circ} \mathrm{E}$ or $270^{\circ} \mathrm{E}$ meridian depending upon the sign of the $h_{2}^{l}$ term and the site hemisphere. The $h_{2}^{I}$ term, however, produces antipodal synthetic VGP paths from sites in opposite hemispheres, unlike the observed VGP paths for DSDP 609 and V16-58 which fall very close to one another. Therefore it appears that a time invariant $h_{2}^{I}$ term can not account for the symmetry about the Equator suggested by these three records. We note that the $h_{2}$ term belongs to the dipole symmetry family, and therefore within the context of the reversal model proposed by Merrill and MacFadden [1988] in which a reversal results from a critical interaction between the dipole and quadrupole symmetry families, it is possible for the $h_{2}^{l}$ term to change sign during the reversal process.

The available Matuyama-Brunhes records from other longitudinal sectors, however suggest that the same sense of symmetry observed in the Atlantic may not have been present along all lines of longitude (e.g. Boso Peninsula, Japan; [Niitsuma 1981], Lake Tecopa, Califomia; [Valet et al., 1988], Tahiti; [Chauvin et al., 1990; Roperch et al., 1990]). Instead the well developed symmetry in the Atlantic may prove to be a regional feature of the transitional field. If so, it may provide some insight into the geographical character of the reversal process. It is interesting to note that two independent efforts to model Matuyama-Brunhes transition records using phenomenological models [Hoffman, 1979; Kaiser and Verosub, 1985] obtained best fits to the observed data if the reversal was initiated at locations within the Earth's outer core along the $330^{\circ} \mathrm{E}$ longitude, within the Atlantic sector. Although these other records do not exhibit the same sense of symmetry about the Equator as observed in the Atlantic sector, there does appear to be a tendency for the transitional VGPs from these records to cluster about two longitudinal bands which include the VGP paths from the Atlantic sector sites [Clement, 1989]. A more quantitative treatment of the relation between the symmetry observed in the transition records from the Atlantic and the rest of the available Matuyama-Brunhes transitions is presented in a separate paper [Clement, in press].

Northern hemisphere records of the upper Olduvai reversal recorded in the Pacific, Italy and the North Atlantic [Helsley et al., 1989; Clement and Kent, 1986] exhibit longitudinally constrained portions of VGP paths which are centered over the Americas. Although the VGP path from a detailed record of this reversal from the southern hemisphere (RC14-14; Clement and Kent, 1985] does not track through the Americas, the 
grouping of the VGP paths from the northern hemisphere records of the upper Olduvai imply an important similarity with the Matuyama-Brunhes transitional field. This observation supports suggestions that similarities in the reversal process may persist through several polarity reversals [Valet et al, 1984], implying the existence of some long-lived geographical control over the reversal process, resulting perhaps from heterogeneities in the mantle.

\section{Conclusions}

When the southern hemisphere record of the MatuyamaBrunhes transition presented here, which exhibits VGPs tracking northward through the Americas, is considered together with recently obtained records from the equatorial and mid-notthem latitude Atlantic from the same longitudinal sector, an important non-zonal symmetry of the transitional field is suggested. The VGP path from the equatorial record is nearly antipodal to the records from the mid-northern and southern hemispheres, tracking northward through Asia. These records suggest that the transitional field was dominated by non-dipolar non-zonal terms which are symmetric about the equator.

Acknowledgements. We thank William Witte and Doris Lafferty who sampled the core and conducted the laboratory measurements. Two anonymous reviewers provided suggestions which improved the manuscript. This work was supported by NSF grants EAR87-20897 to BMC and EAR8817773 to DVK. Lamont-Doherty Geological Observatory contribution number 4700 .

\section{References}

Bogue, S. W. and K.. A. Hoffman, Morphology of Geomag netic Reversals, Rev. Geophys, 25, 910-916, 1987.

Chauvin, A., P. Roperch, and R. A. Duncan, Records of Geomagnetic reversals from volcanic islands of French Polynesia, 2, Paleomagnetic study of a flow sequence (1.2 $0.6 \mathrm{Ma}$ ) from the island of Tahiti and discussion of reversal models, J. Geophys. Res., 95, 2727-2752, 1990.

Clement, B. M., Geographical distribution of transitional VGPs: Evidence for non-zonal symmetry during the Matuyama-Brunhes geomagnetic reversal, Earth Planet. Sci. Lettt., in press.

Clement, B. M., Longitudinal distribution of BrunhesMatuyama transition VGPs, Eos Trans. $A G U, 70,1073$, 1989.

Clement, B. M., D. V. Kent, and N. D. Opdyke, BrunhesMatuyama polarity transition in three deep-sea sediment cores, Phil. Trans. R. Soc. of London, A306, 113-119, 1982.

Clement, B. M. and D. V. Kent, A detailed record of the lower Jaramillo polarity transition from a southern hemisphere deep-sea core, J. Geophys. Res. 89, 1049 1058, 1984.

Clement, B. M. and D. V. Kent, Geomagnetic polarity transition records from five hydraulic piston core sites in the North Atlantic, In Ruddiman, W. F., Kidd, R. B., Thomas, E., et al., Init. Repts. DSDP 94: Washington (U.S. Government Printing Office), 831-852, 1986.

Clement, B. M. and D. V. Kent, A comparison of two sequential geomagnetic polarity transitions (upper Olduvai and lower Jaramillo) from the southern hemisphere, Phys. Earth Planet. Ints., 39, 310-313, 1985.

deMenocal, P. B., W. F. Ruddiman and D. V. Kent, Depth of post-depositional remanence acquisition in deep-sea sediments: a case study of the Brunhes-Matuyama reversal and oxygen isotopic stage 19, Earth Planet. Sci. Lett, 99, 1$13,1990$.

Fuller, M. , I. Williams, and K. A. Hoffman, Paleomagnetic records of geomagnetic field reversals and the morphology of the transitional fields, Revs. Geophys. Space Phys., I7, 179-203, 1979.

Helsley, C.E., E. Herrero-Berveral, B. Keating, M. Fuller and C. Laj, Reliability of deep-sea polarity transition records. EOS Trans. AGU., 70, 1072-1073, 1989.

Herrero-Bervera, E., and C. E. Helsley, Comparison of deepsea reversal records between the onset and termination of the Olduvai subchronozone, EOS Trans.AGU, 70, 1072, 19.89.

Hoffman, K. A., Polarity transition records and the geomagnetic dynamo, Science, 196, 1329-1332, 1977.

Hoffman, K. A., Behavior of the geodynamo during a reversal: a phenomenological model, Earth Planet. Sci. Lett., 44, 7-17, 1979.

Hoffman, K. A. and M. Fuller, Transitional field configurations and geomagnetic reversal, Nature, 273, 715-718, 1978.

Kaiser, A. D. and K. L. Verosub, Modeling polarity transition with radial dipole soureces: geomagnetic field behavior at northern mid-latitudes, Geophys. Res. Lett., 12, 777-780, 1985.

Livermore, R. A., F. J. Vine, and A. G. Smith, Plate motions and the geomagnetic field, I. Quaternary and late Tertiary, Geophys. J. R. astr. Soc., 73, 939-961, 1983.

Merrill, R. T. and P. L. McFadden, Secular variation and the origin of geomagnetic reversals, J. Geophys. Res., 93, 11589-11598, 1988.

Morley, J. and J. D. Hays, Climatic variations during the last 700,000 years: a faunal and oxygen isotope analysis, GSA abstracts with programs, $8,1019-1021,1976$.

Niitsuma, N., Detailed study of the sediments recording the matuyama-Brunhes geomagnetic reversal, Tohuku Univ. Sci. Rept. 2nd Ser. (Geology), 43, 1-39, 1971.

Raisbeck, G. M., F. Yiou, D. Bourles, and D. V. Kent, Evidence for an increase in cosmogenic ${ }^{10} \mathrm{Be}$ during a geomagnetic reversal, Nature, 315, 315-317, 1985.

Rochette, P., Rationale of geomagnetic reversals versus remanence recording processes in rocks, a critical review, Earth Planet. Sci. Lett., 98, 33-39, 1990.

Roperch, R. and R. A. Duncan, Records of Geomagnetic reversals from volcanic islands of French Polynesia, 1, Paleomagnetic study of a polarity transition in a lava sequence from the island of Huahine, J. Geophys. Res., 95, 2713-2726, 1990.

Schneider, D. A. and D. V. Kent, The time-averaged paleomagnetic field, Rev. Geophys., 28, 71-96, 1990.

Williams, I. and M. Fuller, Zonal harmonic models of reversal transition fields, $J$. Geophys. Res., 86, 11657-11665, 1981.

Valet, J.-P., L. Tauxe and B. M. Clement, Equatorial and midlatitude records of the last geomagnetic reversal from the Atlantic Ocean, Earth Planet. Sci. Lett., 94, 371-384, 1989.

Valet, J.-P., L. Tauxe and D. Clark, The Matuyama-Brunhes transition recorded from the lake Tecopa sediments (California), Earth Planet Sci. Lett., 87, 463-472, 1988.

Valet, J.-P. and C. Laj, Invariant and changing transitional field configurations in a sequence of geomagnetic reversals., Nature, 311, 552-555, 1984.

B. M. Clement, Department of Geology, Florida International University, Miami, FL, 33199

D. V. Kent, Lamont-Doherty Geological Observatory and Department of Geological Sciences, Columbia University, Palisades, NY, 10964

(Received August 15, 1990;

Revised November 6, 1990;

Accepted November 20, 1990.) 